\title{
Why Spanish Working Fathers Do not Request the Reconciliation Measures Available in Their Companies?
}

\section{Sabina Belope-Nguema, ${ }^{1}$ José Andrés Fernández-Cornejo, ${ }^{* 2}$ Lorenzo Escot, $^{3}$ and Eva Del Pozo-García ${ }^{4}$}

Many working fathers would be potential users of the existing reconciliation measures but they do not request them. One barrier they encounter is the lack of sensitivity on the part of corporate culture to men who want to balance work and family life. We use a sample of Spanish wage-earner fathers and path analysis to analyzefollowing Sen's capability approach-how companies that support the use of reconciliation measures by fathers can reduce the gap between theoretical rights to and effective use of reconciliation measures, which leads to a decrease in levels of work-family conflict experienced by these working fathers.

\section{Introduction}

Empirical evidence seems to indicate that there is an increase in the percentage of men, and particularly fathers, who feel they experience significant work-family conflict (WFC). In fact, some studies find that men now experience more WFC than women.

In the Sixth European Working Conditions Survey 2015 (Eurofound 2016) the following question was put to the respondents: "How often in the last twelve months have you found that your job prevented you from devoting the time you wanted to your family?" The percentage of men answering "always/ most of the time/sometimes" was greater than that for women who answered the same in twenty-one of the thirty-three countries analyzed.

According to Aumann, Galinsky, and Matos (2011), in the United States the percentage of fathers (with children under eighteen) in dual earning couples

\footnotetext{
${ }^{1}$ Departamento de Estadística e Investigación Operativa III, Universidad Complutense de Madrid, Madrid, Spain ${ }^{2}$ Departamento de Economía Aplicada, Pública y Política, Universidad Complutense de Madrid, Pozuelo de Alarcón, Spain

${ }^{3}$ Departamento de Economía Aplicada, Pública y Política, Facultad de Estudíos Estadísticos, Universidad Complutense de Madrid, Madrid, Spain

${ }^{4}$ Departamento de Economía Financiera y Métodos de Decisión, Universidad Complutense de Madrid, Pozuelo de Alarcón, Spain

*joaferna@ucm.es
} 
reporting WFC was 35 percent in 1977 and 60 percent in 2008; this compares with the case of mothers, where the corresponding numbers were 41 and 47 percent.

On the other hand, in accordance with the sample of fathers and mothers (with children under six) from the region of Madrid (Spain) used in this article, there were more wage-earner fathers (60.1 percent) than wage-earner mothers (48.1 percent) who were strongly or somewhat in agreement with the statement that "the amount of time my job takes up makes it difficult to fulfill family responsibilities."

Why does this greater conflict between work and family occur among male parents?

Nowadays, "being a good father" is not just identified with the need to be a breadwinner but also with the need to be a fully involved father from the beginning in the care and cognitive and affective development of the children. There are rising expectations and norms for men to become carers (Adler and Lenz 2017; Aumann, Galinsky, and Matos 2011; Kimmel 2017, chap. 6). This coincides with the rise of the figure of the "new father" or "superdad" (Abril, Jurado-Guerrero, and Monferrer 2015; Kaufman 2013).

But the remaining pressure to be an "ideal worker," fully committed to the company, with long and inflexible working days, etc., and simultaneously to be an involved father can give rise to tension which translates into growing WFC (Gatrell et al. 2015; Rehel and Baxter 2015).

A question arising in this context is why many fathers with a right (and also an inclination) to make use of reconciliation measures (as a way to reduce this WFC) very rarely request them?

Many fathers who would be potential users of the existing reconciliation measures do not request them because they feel that these measures "are not for them." Here there is a convergence of attitudes (still influenced by traditional gender norms) and the ignorance of many fathers themselves, with the lack of a sensitive corporate culture concerning the adjustment of men to the use of reconciliation measures. As Burnett et al. (2013) say, "fathers perceive that while family-friendly policies might in theory be available to parents, they are in practice targeted at working mothers" (see also Gatrell et al. 2015). This implies that many men are not yet able to publicly identify themselves at the workplace as parents (and request the corresponding family-friendly policies).

This lack of sensitivity on the part of corporate culture with regard to males wishing to balance work and family is a barrier that inhibits the fathers' use of reconciliation measures, and thus creates an agency gap in work-family balance. That is to say, a gap exists between the theoretical right to use these measures and the real ability to do so. The analysis of this agency gap in work-family balance can be dealt with by applying Amartya Sen's capabilities framework (Drobnič and Guillén-Rodríguez 2011; Hobson and Fahlén 2009; Hobson 2011; Sen 1993). 
Sen's framework of capabilities and agency provides the theoretical space for capturing this growing divide between rising expectations and norms for men to become carers and earners and the economic, social, and normative barriers that they encounter (Hobson 2011). One of these barriers is a workplace one: the bias against fathers' reconciliation (lack of sensitivity on the part of corporate culture to men who want to balance work and family).

In this article, we are going to use a sample of wage-earning fathers (and their partners) living in the region of Madrid (Spain). Our purpose is to analyze, on the one hand, according to the perceptions of these fathers, to what extent family-friendly companies (or family-supportive organizations) are workplaces with lower bias against father's reconciliation. And, on the other hand, to what extent does lack of firms' sensitivity toward reconciliation of male staff (bias against fathers' reconciliation) acts as a barrier to the use of these measures by men, which creates a gap between theoretical rights and real capacity to use them, which leads to increasing levels of WFC.

\section{Spanish Context}

In Spain, there is a complex labor market characterized by structurally high unemployment rates and important levels of job insecurity. These problems were accentuated during the 2008-2013 economic crisis (regarding the consequences of the economic crisis on changes in work-family arrangements in Spain, see Dotti 2017). During the conduct of the survey (2016) used in this article, the macroeconomic situation was one of gradual economic recovery, but without having reached even the 2007 employment levels (OECD 2017).

Spain is a Mediterranean Latin country that until the 1970s was a very traditional society with a largely traditional division of household labor, with strong family values, but where, since the end of dictatorship (1975), values and social norms (including gender norms) have been evolving quite quickly toward those existing in the most advanced societies (Fernández-Cornejo et al. 2016b; Moreno, Ortega, and Gamero-Burón 2017; Valiente 2013).

Although attempts have been made to apply good reconciliation policies (especially in large companies), in general, the social and media discourse in favor of work-family balance does not seem to have penetrated sufficiently in society. In Spain, the reconciliation of work and family life is very complicated for most parents (Goñi-Legaz and Ollo-López 2016). Working hours in Spain do not facilitate work-family balance. Lunch is usually taken later than in the rest of the world and the working day is usually extended excessively in the afternoon (perhaps because Spain follows Central European Time but is geographically closer to GMT). These problems combined with a chronic lack of childcare facilities (for children under three) often means that working parents have problems taking care of their children during the week. As the participation of men in domestic and care work is still low, this situation particularly affects working 
mothers. Often the way of making work compatible with childcare is to turn to intergenerational solidarity (help from grandparents, particularly grandmothers) (Pérez-Caramés 2014).

According to Moreno, Ortega, and Gamero-Burón (2017), currently in Spain there is an ambivalent coexistence of two family models- the traditional care model and the dual-earner (care responsibility of both man and woman) family model. This may be consistent with an emerging change in fathers' attitudes toward a more involved fatherhood. In a qualitative study of Spanish fathers, Abril, Jurado-Guerrero, and Monferrer (2015) found that approximately one-third of their sample held ideas quite in agreement with new parenting roles; and even the rest of the fathers - who had more adaptive attitudes-held that they wanted to be very involved in the life of their children. In addition, the discourse on gender equality and the public equality policies place more emphasis on the need to advance in the domain of shared responsibility between women and men in domestic and care work.

The Equality Law introduced in 2007 a paternity leave (paid at 100 percent with a ceiling, and nontransferable) of thirteen days. In addition, when becoming fathers, salaried men are entitled to a two-day leave paid by the company. So male employees had in 2016 (the year in which our survey was conducted) fifteen days of leave after having or adopting a child. This is the only leave used by most eligible fathers (Meil, Romero-Balsas, and Rogero-García 2017a). Mothers have a maternity leave of sixteen weeks (paid at 100 percent with a ceiling). The first six weeks are compulsory and the other ten can be transferred to the father. This last option is hardly used (out of a total of 273,032 maternity leaves completed in 2016, only 5,233 were shared with the father). The same applies to the "nursing leave" (two half-hour paid breaks per day until the baby is nine months old or two additional weeks of leave paid by the company) and to the "unpaid leave," which can be used until the child is three years old. Other statutory reconciliation measures, such as the right to reduce working hours for childcare are also used to a very limited extent by fathers.

In January 2017, paternity leave was extended by two more weeks, so that from this date (outside our sampling period) fathers have four weeks. Currently there is debate about the possibility of equating paternity leave with maternity leave, although this is a rather low-profile social demand, compared to other debates and political problems that exist today in Spain.

With regard to the family-friendly measures (FFMs) offered by companies, on the one hand, there is a growing awareness of the need to create a familyfriendly culture; and, on the other, FFMs tend to be more important in large organizations than in small organizations (Pasamar and Alegre 2015). The most-used FFMs are those related to flexible working arrangements (especially flexible start and finish times). Other forms of flexibility that can be found in some companies are: compressed work week, remote working, teleworking, and shift changes. Some companies have some form of childcare assistance and others have some measures for extending paid family leave. 
These aspects corresponding to the Spanish population, in general, acquire particular importance in the case of our sample of fathers living in the region of Madrid. This sample allows us to have data on a population in which there is a growing number of fathers wanting to be involved in caring, in the context of a labor market that is not sensitive to the parents' reconciliation needs (Conde-Ruíz and Marra 2016), in general, and of the fathers, in particular. That is, we work with a sample where the context might be characterized by a marked gap between expectations and capacity of choice. This is a very interesting situation from the point of view of research, and may be representative of a series of emerging and advanced countries where there is an important gap between some attitudes which are changing rapidly and institutions and business culture that change more slowly. For instance, 63.6 percent of our sample of wage-earning fathers agreed with the statement "there will come a time in the future in which men will use as much as women the measures of reconciliation of family and working life offered by companies." But, in contrast, only 4 percent of them asked for a reduction in working hours after the birth of their last child, while 37.7 percent of mothers asked for this.

\section{Theoretical Justification and Review of the Literature}

\section{Work-Family Balance}

There is an extensive literature on work-life balance, originating in the late 1960s (Pasamar and Alegre 2015). However, defining "balance" is not easy. Allen and Greenhaus (2011) distinguish three notions of work-family balance which are normally used in the literature on this subject: balance as the absence of WFC; balance as high involvement across multiple roles; and balance as high effectiveness and satisfaction across multiple roles. On this basis, these authors define work-family balance as "an overall appraisal of the extent to which individuals' effectiveness and satisfaction in work and family roles are consistent with their life values at a given point in time."

This definition is consistent with the work-family border theory (Clark 2000) and with the boundary theory (Ashforth, Kreiner, and Fugate 2000). Both theories address how people construct, maintain, negotiate, and cross boundaries or borders between work and family.

Two sides can be distinguished in the work-life interface: work-family conflict and work-family enrichment. Greenhaus and Beutell (1985) define work-family conflict as a form of inter-role conflict in which the role pressures from the work and family domains are mutually incompatible in some respect. Depending on the origin of the interference, we can distinguish between work-to-family conflict and family-to-work conflict. On the other hand, Greenhaus and Powell (2006) define work-family enrichment as the extent to which experiences in one role improve the quality of life in the other role. The causality can be work-to-family benefit and family-to-work benefit. 
In this article, emphasis is placed on work-family conflict understood as work-to-family conflict. Although several sources of WFC have been identified, most researchers agree that WFC exists when (Greenhaus and Beutell 1985): (a) time devoted to the requirements of one role makes it difficult to fulfill requirements of another; (b) strain from participation in one role makes it difficult to fulfill requirements of another; and (c) specific behaviors required by one role make it difficult to fulfill the requirements of another.

We use the Work-Family Conflict Scale developed by Netemeyer et al. (1996) that incorporates items from these three sources.

\section{Fatherhood and Identity}

A classical conceptualization of paternal involvement in the literature has been the one offered by Lamb et al. $(1985,1987)$. They proposed that paternal involvement consisted of three dimensions: interaction (father's direct contact with his child through caring and shared activities); availability (potential availability for interaction, accessibility to the child); and responsibility (e.g. making decisions for the child). Implicit in these dimensions is the notion of positive paternal involvement, which is likely to promote healthy development in the child (Habib 2012).

The effective involvement of the father is influenced by a series of demographic and work characteristics that have to do with economic constraints and the division of labor and childcare between the members of the couple (Lapuerta 2013; Meil 2013; Meil, Romero-Balsas, and Rogero-García 2017b). But the fathers' social psychological characteristics, such as their father identity, are also very important (Goldberg 2015).

One way to deal with the analysis of the father's identity is the one derived from Stryker's identity theory (1968), a theory based on symbolic interactionism. This approach has been used by various authors (Goldberg 2015; Habib 2012; Olmstead, Futris, and Pasley 2009) to explain the father's involvement, or his wish to be involved.

The identity theory states that individuals' identities and roles are organized hierarchically, and that the position of a particular identity (or role) in this hierarchy predicts how often individuals will act in accordance with that identity (Goldberg 2015). The position in this hierarchy of an identity may be influenced by its salience (the likelihood that an identity is invoked in a particular situation) and its psychological centrality (the psychological importance of identities according to individuals themselves). In this sense, and at least in most advanced countries, the status of an involved father may nowadays be more prominent (more salient and psychologically central) than before.

This greater prominence of the involved father may be related with the emergence of the figure of the "new father" or "superdad" (Bonney, Kelley, and Levant 1999; Devreux 2007; Fursman and Callister 2009; O'Brien and Moss 2010; Romero-Balsas, Muntanyola-Saura, and Rogero-García 2013), who is a direct and involved carer of his children. 
In the case of the United States, Kaufman (2013) conducted seventy semistructured interviews with fathers. She differentiated three types of fathers: "old dads" (traditional fathers), "new dads" (fathers who seek a better workfamily balance), and "superdads" (fathers who significantly adjust their work to have more time with their families). One of her conclusions was that "there has been a particularly strong shift in men's attitudes that has brought convergence (with mothers) in beliefs about work and family roles."

For the case of Spain, Romero-Balsas, Muntanyola-Saura, and RogeroGarcía (2013) analyzed (on the basis of an analysis with thirty in-depth interviews) how Spanish fathers constructed and justified their decisions to use parental leaves. They identified a minority group of "new fathers" with a clear procare discourse and a discursive awareness of the need to balance personal, family, and work time. Furthermore, Abril, Jurado-Guerrero, and Monferrer (2015) in their qualitative study with sixty-eight couples identified three types of fathers: "occasional caregivers," "assisting caregivers" (the father helps the mother, who has the main responsibility of caring), and "committed fathers" (fathers fully committed with an involved paternity). According to Abril, Jurado-Guerrero, and Monferrer (2015), "this form of committed paternity is increasingly present in young Spanish fathers."

Summarizing, the literature seems to indicate that there is a growing number of fathers who feel they should be actively involved in looking after their small children, and so are potential users of reconciliation measures.

\section{Corporate Barriers to Fathers' Reconciliation}

With respect to these barriers in the workplace that affect male workers in particular, in this work we use the expression "bias against fathers' reconciliation." We define it as the viewpoint held by managers of organizations and fellowworkers that the need for reconciling, and the WFC, are questions specifically relating to women staff and not so much to men staff. Or, from the fathers' point of view, the perception held by these fathers that the reconciliation measures "are not for them" (they do not feel entitled). This idea appears in the works of Abril and Romero (2008), Burnett et al. (2013), Bustelo and Peterson (2005), Gatrell et al. (2015), Haas and Hwang (2007), Holter (2007), and Levine and Pittinsky (1997).

Levine and Pittinsky (1997) referred to the simultaneous action of three factors which are self-reinforcing among each other: males do not request reconciliation practices because they feel that these measures are not available for them; employers do not openly offer these to males because they do not seem to ask for them; and since they do not, women ask for these reconciliation practices in a context of social pressure leading them to do so, as well as the fact that they are available in their organizations. Moreover, this coincidence of factors does not just occur between management and male workers, men also feel themselves pressured by their own co-workers, who sometimes do not understand that they want to balance family and work. 
Burnett et al. (2013) use qualitative interview data drawn from one hundred employed fathers from two large UK organizations. These authors try to show that while male workers may feel valued as employees, they often feel invisible at work in their paternal role: "While work-family policies typically proclaim themselves to be gender neutral, many are still (perhaps inadvertently) developed and written to be utilized in conjunction with motherhood, rather than fatherhood."

Kaufman (2013), in her interviews, found that some fathers had the perception that their companies were "resistant workplaces": "Some men feel discouraged by employers and co-workers from taking leave. Employers may resist the notion that fathers want to be actively engaged in family life."

In this article, we are going to construct two instruments in order to introduce some elements of these workplace barriers in our analysis: "Reconciliation bias" (perception by the respondent that in his company there is a bias against fathers' reconciliation); and "exemplarity" (extent to which in the respondent's company the managers use reconciliation measures).

\section{WFC Among the Fathers}

As mentioned at the beginning, nowadays it seems that there is a growing number of fathers who feel they experience a high level of WFC. And this is so because today "being a good father" not only is identified with the need of being a breadwinner but also with the need to be a completely involved father, from the start, in caring and in the cognitive and affective development of their children. O'Brien and Moss (2010), referring to the case of Europe, state that "today fathers are expected to be accessible and nurturing as well as economically supportive to their children." And Kaufman (2013), referring to the case of United States, affirms that "fathers are expected to work long hours but are also expected to be highly involved with their children."

Despite a dramatic shift in attitudes, workplaces are still largely organized for the so-called ideal worker - an individual who is unencumbered by family responsibilities (Rehel and Baxter 2015). This strong inertia of the culture of the ideal worker acts in unison with some workplaces in which, in practice, reconciliation measures are used very much in the minority by male workers (and very much in the majority by female workers). As a result many fathers who would be potential users of existing reconciliation measures forbear to do so, thus creating a growing subjective sensation of WFC.

An interesting aspect for analysis is the role played in this context by family-friendly workplaces. In particular, we are interested in finding out if firms with a family-supportive work environment are companies with a lower degree of bias against fathers' reconciliation and lower levels of WFC among fathers (Escot et al. 2012). We used the Family-Supportive Organizational Perceptions (FSOP) scale (Allen 2001). This scale has previously been used in other research works, such as that of Grandey, Cordeiro, and Michael (2007). 


\section{Gap Between Theoretical Rights and Choice: Sen's Capability Approach}

Sen's capability approach (Sen 1989, 1999) is a normative theory (in the field of the theories of the economic and social justice) based on the assessment of individuals' capabilities (their opportunities to achieve valuable "functionings" or "states of being") (Sugden 1993). It asks us to consider not only what individuals do but also what their opportunities to be and do are. For Sen, the core issue is not only what individuals choose, but the choices that they would make if they had the capabilities of achieving the kind of lives that they have reason to value (Robeyns 2003).

Sen starts from the idea that living may be seen as consisting of a set of interrelated "functionings," consisting of "beings" and "doings" (being adequately nourished, avoiding premature mortality, being able to read and write, being happy, etc.). Functionings are to be distinguished from commodities: a commodity is an object which a person might use, while a functioning is an aspect of living itself (Sugden 1993).

Capability refers to the set of valuable functionings that a person has effective access to. Thus, a person's capability represents the effective freedom (or agency) of an individual to choose between different functioning combinations. If this capability set is expanded, the well-being of the individual can be increased.

Sen's capability approach can be a useful theoretical framework for analyzing agency inequalities in work-family balance (Drobnič and GuillénRodríguez 2011; Hobson 2011; Hobson and Fahlén 2009). There exists a gap between fathers' theoretical rights to use reconciliation measures and the effective ability to use them (this giving rise to growing levels of WFC).

Hobson (2011) distinguishes three types of factors which determine the individual's capability set (based on a reformulation of the "conversion factors" proposed by Sen): individual factors (gender, ethnicity, age, human capital, etc.); institutional factors (laws, policies, organizational culture, etc.); and social/cultural factors (society, community, media, public debate, etc.).

In this article we consider that "being effectively able to balance work and family" is a "functioning" that can be achieved (at least in part) through the use of the reconciliation measures offered by companies. And we consider that an important factor to access this functioning (to give the individual the capability of achieving that functioning) is the fact of working in an environment where there is a low (or null) level of bias against fathers' reconciliation. That is to say, if the workplace (the corporate culture) is sensitive to the need of using the reconciliation measures by the fathers, that means that the capabilities of the fathers (their agency to choose) will be expanded. And if the fathers have the feeling/ perception that they can effectively use these reconciliation measures, the rate of use of them will increase and the subjective perception of WFC will decrease.

We are going to focus our analysis in the family-supportive and fathersupportive culture of companies, but we will also consider other factors (as 


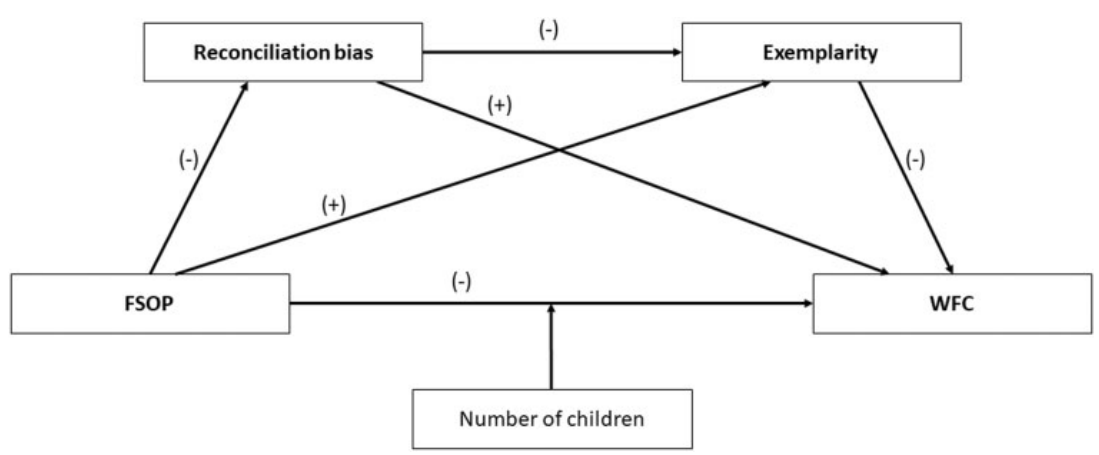

Figure 1 Hypothesized model of the determinants of WFC.

Notes: Control variables are "Public sector," "Working week," "Daily hours caring," "Earnings," "Size of the organization," and "Mother's satisfaction with family."

control variables) that also can expand the capability of fathers to reach a work-family balance (expressed as a reduction in WFC).

\section{Model and Hypotheses}

\section{Hypothesized Model}

The purpose of the model is to show that, according to the perceptions of the fathers, the family-supportive organizations are workplaces that reduce WFC, directly and indirectly, through a reduction in the bias against the father's reconciliation.

In figure 1, we present our hypothesized model. The dependent variable is WFC (father's perception of WFC). This WFC is explained by the FSOP, "Reconciliation bias" (bias against fathers' reconciliation), and "Exemplarity" (extent to which in the respondent's company men and male managers use reconciliation measures). The variable "Exemplarity" has a direct negative effect on WFC. The variable "Reconciliation bias" has a positive direct effect on WFC and a positive indirect effect on WFC through the mediator variable "Exemplarity" (in our model we assume that firms with high levels of bias against fathers' reconciliation are companies in which men and male managers make low use of reconciliation measures). And the variable FSOP has a negative direct effect on WFC and a negative indirect effect on WFC through the mediating variables "Reconciliation bias" and "Exemplarity." We also consider that the direct effect of FSOP on WFC can be moderated by the number of children (the higher the number of children, the higher the direct effect of working in a family-supportive company on reducing WFC). 


\section{Contrasting Hypotheses}

Hypothesis 1. Working in a firm where there is lower bias against fathers' reconciliation and a greater effective use of reconciliation measures by other men and male managers reduces the feeling of WFC among male workers. Indeed, a lower value in the "Reconciliation bias" variable and a higher value in the "Exemplarity" variable constitutes an indicator that the firm's corporate culture provides a "factor" or "resource" for the firm's male workforce which expands their ability to choose in the field of reconciliation. In other words, that support of the company for the reconciliation of men reduces the gap between theoretical rights to and effective use of reconciliation measures. This smaller gap should lead to a use of reconciliation methods nearer to the optimum level, thus reducing the feeling of WFC. In the context of our model fathers who have the idea that the place where they work has a low level of "Reconciliation bias" and a high level of "Exemplarity" will tend to have a lower feeling of WFC.

Hypothesis 2. Male workers working in firms where reconciliation bias is low have the perception that in their firms there is a greater effective use (and exemplarity in the use) of reconciliation measures by men and male managers. Indeed, the "Exemplarity" variable mediates the effect of "Reconciliation bias" on WFC. That is, a lower value of "Reconciliation bias" also tends to indirectly reduce the WFC value through its effect on "Exemplarity."

Hypothesis 3. The family-supportive organizations are also firms in which corporate barriers to male reconciliation are lower. Specifically, fathers working in FSOP firms have the perception that in their firms there is less bias against father's reconciliation and greater effective use of reconciliation measures by men and male managers.

Hypothesis 4. Being a family-supportive organization reduces fathers' WFC directly, but also indirectly, through its effect on bias against father's reconciliation ("Reconciliation bias") and the firm's exemplarity ("Exemplarity").

Hypothesis 5. The direct effect of the FSOP on the WFC is moderated by the number of children. The greater the number of children, the greater the need to reconcile, so the greater will be the degree to which working in a family-supportive organization will reduce the father's feeling of WFC.

\section{Data and Methods}

\section{Database}

Data were collected (from February to May 2016) from 1,785 households with children between three and six years old, residing in Madrid and its metropolitan area. Sampling was obtained through fifty-four randomly selected schools belonging to ten homogeneous geographic zones (in terms of the child population). In each of these schools, the teachers distributed the questionnaires among their students (from "3rd year," "4th year," or " 5 th year" of preschool education) for them to give to their parents. Once the 
questionnaires were completed, the children returned them to the teacher in a sealed, anonymous envelope. The rate of response (parents who completed the questionnaire/questionnaires delivered to school management) was 40.5 percent (this rate would be over 50 percent if we take into account that approximately 20 percent of questionnaires delivered to school management were not distributed).

The questionnaire had a closed structure and was divided into three parts: the first one had ten common questions for both parents (household characteristics); the second part had forty questions to be filled out by the father (1,661 fathers completed this part); and the third part had forty-one questions for the mother (1,775 mothers completed this part). Most of these questions addressed to the father and to the mother were the same. The objective was to gather information (from the mother and the father) about how they divided the childcare tasks and about their working lives.

Given the purpose of this article (to analyze the case of fathers working in organizations) we were interested in fathers who were wage-earners at the moment of doing the survey. Thus from the initial sample we selected a sub-sample of 1,264 wage earners fathers (those with no employment and the self-employed were excluded). The average age of the fathers of our sub-sample was 39.8 years; their average number of children was 1.95; 96.5 percent of the fathers lived in the same home with the mother (we did not receive any questionnaire from same-sex couples); 77.4 percent of the mothers had a job; 14.4 percent of the fathers were economic immigrants; and 52.8 percent of the fathers worked in large organizations (we include here most of the fathers who worked in the public sector and those who worked in private companies with more than 250 workers).

\section{Dependent Variable}

In the quantitative analysis that will be developed later the dependent variable will be "WFC" (father's perception of WFC). We used the Work-Family Conflict Scale of Netemeyer et al. (1996), which is a measure consisting of five items.

The respondent was being asked "To what extent do you agree or disagree with each of these statements?" These statements were responded to along five-point strongly disagree-strongly agree response scales. The five statements were: "The demands of my work interfere with my home and family life"; "The amount of time my job takes up makes it difficult to fulfill family responsibilities"; "Things I want to do at home do not get done because of the demands my job puts on me"; "My job produces strain that makes it difficult to fulfill family duties"; and "Due to work-related duties, I have to make changes to my plans for family activities."

The measure is the average score of these five items (Cronbach's $\alpha=0.904$ for our sample of wage-earner fathers). The range of values is from one to five (see table 1). The higher the score, the higher the perception of WFC. 


\section{Explanatory Variables}

There are three main explanatory variables ("FSOP," "Reconciliation bias," and "Exemplarity") and several control variables.

FSOP is a measure consisting of fourteen items developed by Allen (2001). The respondents were asked the following question: "To what extent do you agree that each of the following statements represent the philosophy or beliefs of your organization (remember, these are not your own personal beliefs, but pertain to what you believe is the philosophy of your organization)?" The response options were on a five-point strongly disagree-strongly agree scale. Some examples of these fourteen statements were: "It is assumed that the most productive employees are those who put their work before their family life" (reverse scoring); and "Employees are given ample opportunity to perform both their job and their personal responsibilities well." The list with the fourteen statements is in the Appendix. The measure is the average score of the fourteen items (Cronbach's $\alpha=0.823$ ). The range of values is from one to 4.93 (see table 1). The higher the score, the higher the perception of a familysupportive work environment.

"Reconciliation bias" is a measure that was developed from five questions addressed to the respondents that sought to determine whether a father had the perception that in his company there is a bias against fathers' reconciliation. Specifically, the respondents were again asked: "To what extent do you agree that each of the following statements represent the philosophy or beliefs of your organization (remember, these are not your own personal beliefs, but pertain to what you believe is the philosophy of your organization)?" The response options were in a five-point strongly disagree-strongly agree scale. These five statements were: "In my company, the need to reconcile work and family life is conceived as something that concerns mainly the female staff of the company, and not so much the masculine one"; "In my company, it is considered more 'natural' for a mother to apply for a paid leave, unpaid leave or a reduction of working hours to care for small children, than for the father to apply for it"; "A father who uses the reconciliation measures available in the company (working hours reduction, etc.) is seen as an uncompetitive and unambitious worker"; "A father who uses the reconciliation measures available in the company (working hours reduction, etc.) is seen as a rather weak and insecure worker"; and "A father who uses the reconciliation measures available in the company (working hours reduction, etc.) is often seen as someone who 'sneaks off from work for some other purpose." The measure is the average score of the five items (Cronbach's $\alpha=0.910$ ). The range of values is from one to five (see table 1). The higher the score, the higher the respondent's perception that the company does not support fathers' reconciliation.

"Exemplarity" is a measure that was developed from four questions addressed to the respondents that was intended to determine whether a father had the perception that in his company men and male managers routinely use 
S. Belope-Nguema et al.

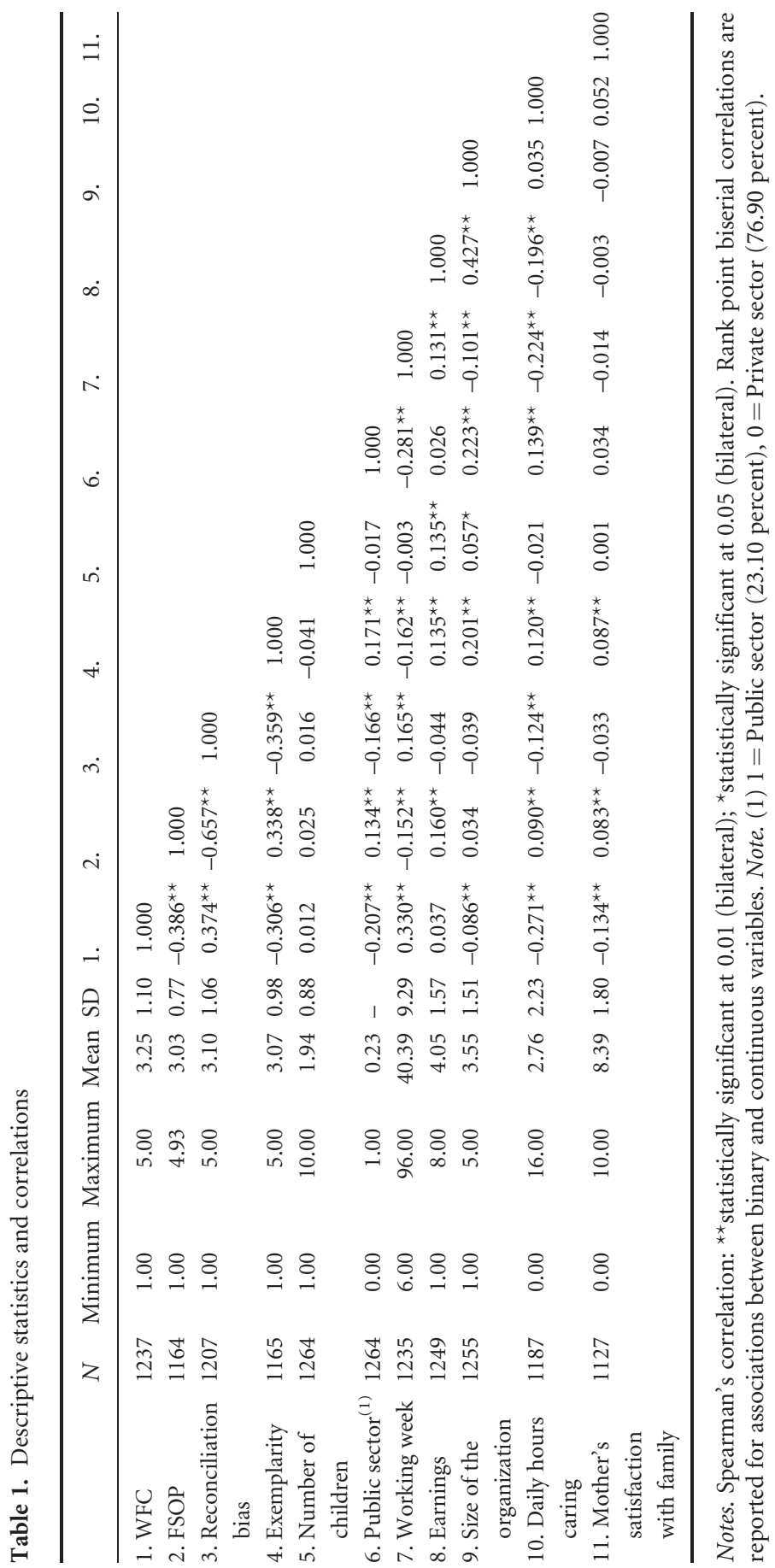


reconciliation measures (are exemplars in this field). The respondents were asked "What is your degree of agreement with these statements about the support of your company/organization to the reconciliation?" The response options were on a five-point strongly disagree-strongly agree scale. These four statements were: "In my company, almost all fathers use paternity leave"; "Most male managers take the full paternity leave when having a child"; "In my company, the percentage of fathers using the reconciliation measures is above the average of other companies"; and "In my company, middle managers are sensitive to the needs of reconciling of male staff." The measure is the average score of the four items (Cronbach's $\alpha=0.783$ ). The values range from one to five (see table 1). The higher the score, the higher the respondent's perception that in the company men and male managers commonly use reconciliation measures.

There is a moderating variable, "Number of children," that we consider moderates the direct effect of FSOP on WFC.

As control variables these six variables were also considered: "Public sector" (father works in the public sector), which is a dichotomous variable ( $1=$ public sector; $0=$ private sector); "Working week" (number of hours the respondent ordinarily works per week); "Earnings" (monthly net income. There are eight categories: from (1) "Fewer than 600 Euros" to (8) "More than 4,000 Euros"); "Size of the organization" (size of the organization where the father works. There are five categories: from (1) "Fewer than ten workers" to (5) "More than 500 workers"); "Daily hours caring" (time that the father usually dedicates to the care of his children, in a working day); and "Mother's satisfaction with family" (mother's degree of satisfaction with her family and personal life; on a scale of zero to ten, where " $0=$ zero satisfaction" and " $10=$ very high satisfaction"). These six variables have a statistically significant effect on at least one of the three endogenous variables of the model. Other possible control variables, such as the fact that the father is an economic immigrant, or the mother's employment status, have not been included as control variables because they did not have a significant effect on any of the three endogenous variables.

\section{Results}

\section{Descriptive Statistics}

The basic descriptive statistics of the eleven variables to be used in our path analysis are shown in table 1 , as well as the corresponding correlations between these variables. Correlations are quite consistent with the relations raised in our hypothesized model. For instance, the model states that there are three explanatory variables ("Exemplarity," "Reconciliation bias," and FSOP) associated with the dependent variable father's perception of WFC; and indeed statistically significant correlations are obtained (with the expected signs) 
between those three variables and the latter (respectively, $r=-0.306$, $p=0.000 ; r=0.374, p=0.000$; and $r=-0.386, p=0.000)$.

On the other hand, most of the control variables used in our analysis also present statistically significant correlations with WFC.

\section{Path Analysis}

Path analysis was conducted using structural equation modeling, through the CALIS Procedure in the SAS v9.4 software package (SAS Institute 2015). The estimation method used was the robust maximum likelihood, which performs robust estimation of model parameters to non-normal data (Finney and DiStefano 2006). The statistical model performed combines a serial multiple two-mediator model with a moderation of only the direct effect, which can be referred to as "conditional process analysis" (Hayes 2013). We estimated the model showed previously in the conceptual diagram (figure 1). The output of our path analysis is in tables 2 and 3.

First, we examined the fit to the data of our hypothesized model of the determinants of father's perception of WFC (figure 1). In an initial version of the model we considered that the five control variables affected the three endogenous variables of the model. But after removing some of these effects (those in which there were not statistically significant results), we arrived to the definitive model as shown in table 2 . The fit of the model was quite acceptable. The chi-square of our model was not significant $\left(\chi^{2}(27)=26.793, p=0.475\right)$, and its fit indices were quite acceptable $(\mathrm{TLI}=1.000 ; \mathrm{CFI}=1.000 ; \mathrm{RMSEA}=0.000$ and $90 \%$ confidence interval (CI) $[0.000,0.026]$; SRMR $=0.020$ ).

Our five contrasting hypotheses appear to be confirmed by the data.

"Reconciliation bias" shows a positive and significant direct effect on "WFC". Indeed, the coefficient (standardized coefficient) for "Reconciliation bias" (in the final model in table 2 ) is positive and statistically different from zero $(\beta=0.138, p=0.001)$. However, "Reconciliation bias" shows also a negative and significant effect on "Exemplarity" $(\beta=-0.253, p=0.000)$. On the other hand, the variable "Exemplarity" has a negative and significant effect on "WFC" $(\beta=-0.145, p=0.000)$. This also means that "Reconciliation bias" has an indirect effect on WFC through the mediating variable "Exemplarity" (indirect effect $=0.037$, bootstrap 95\% CI: 0.019, 0.059; not shown in tables). So the total effect of "Reconciliation bias" on WFC (adding the direct and indirect effects) is 0.175 . Hence, two cases that differ by one standard deviation on "Reconciliation bias" are estimated to differ (in total) by 0.175 standard deviations of WFC.

These results provide evidence in favor of hypothesis 1 . It seems that the fathers of our sample have a lower subjective perception of WFC when they work in companies where they consider there is a minor bias against fathers' reconciliation, and when they observe that the male workers and male managers of their companies usually use reconciliation measures. Indeed, a lower 


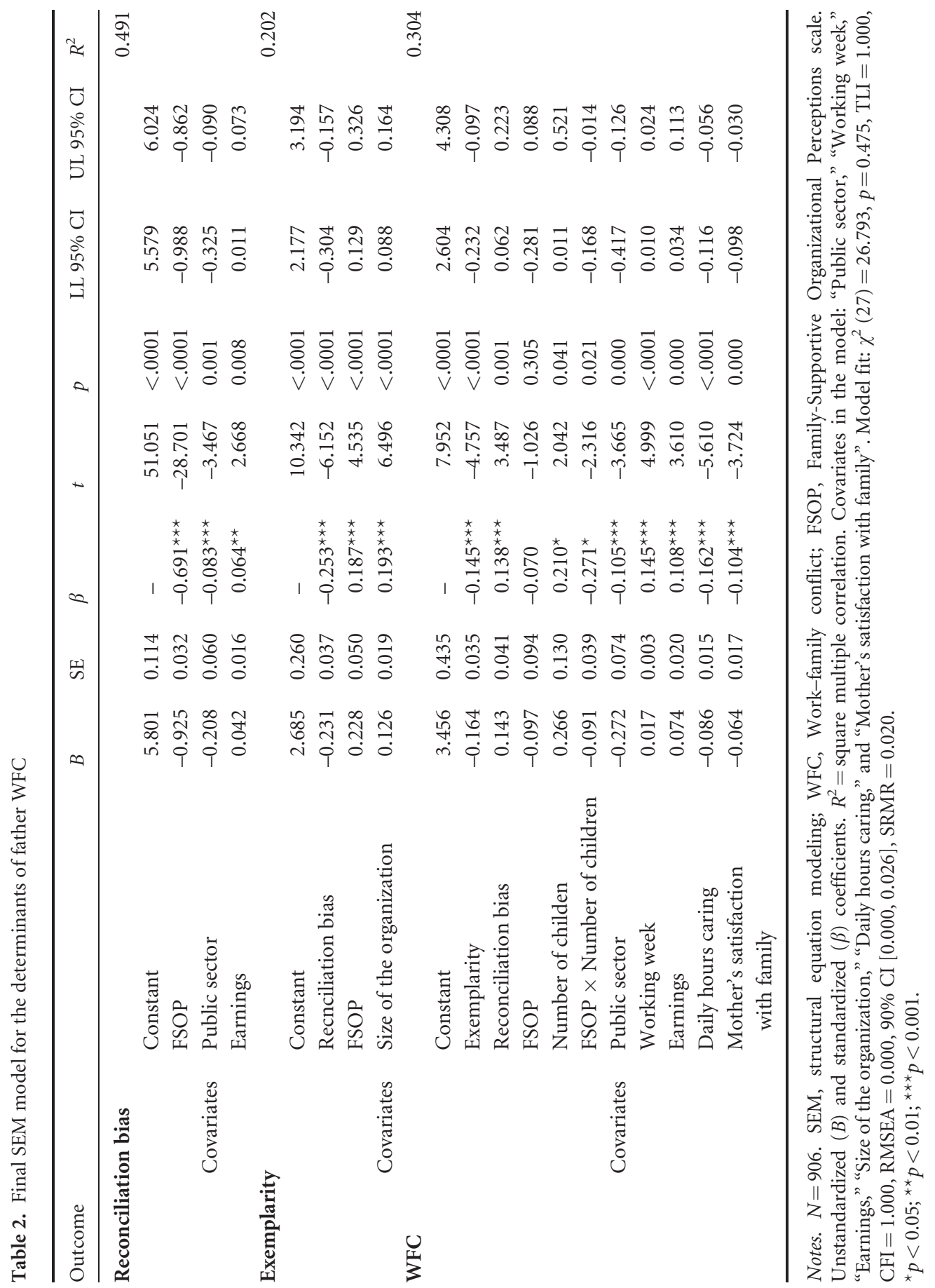




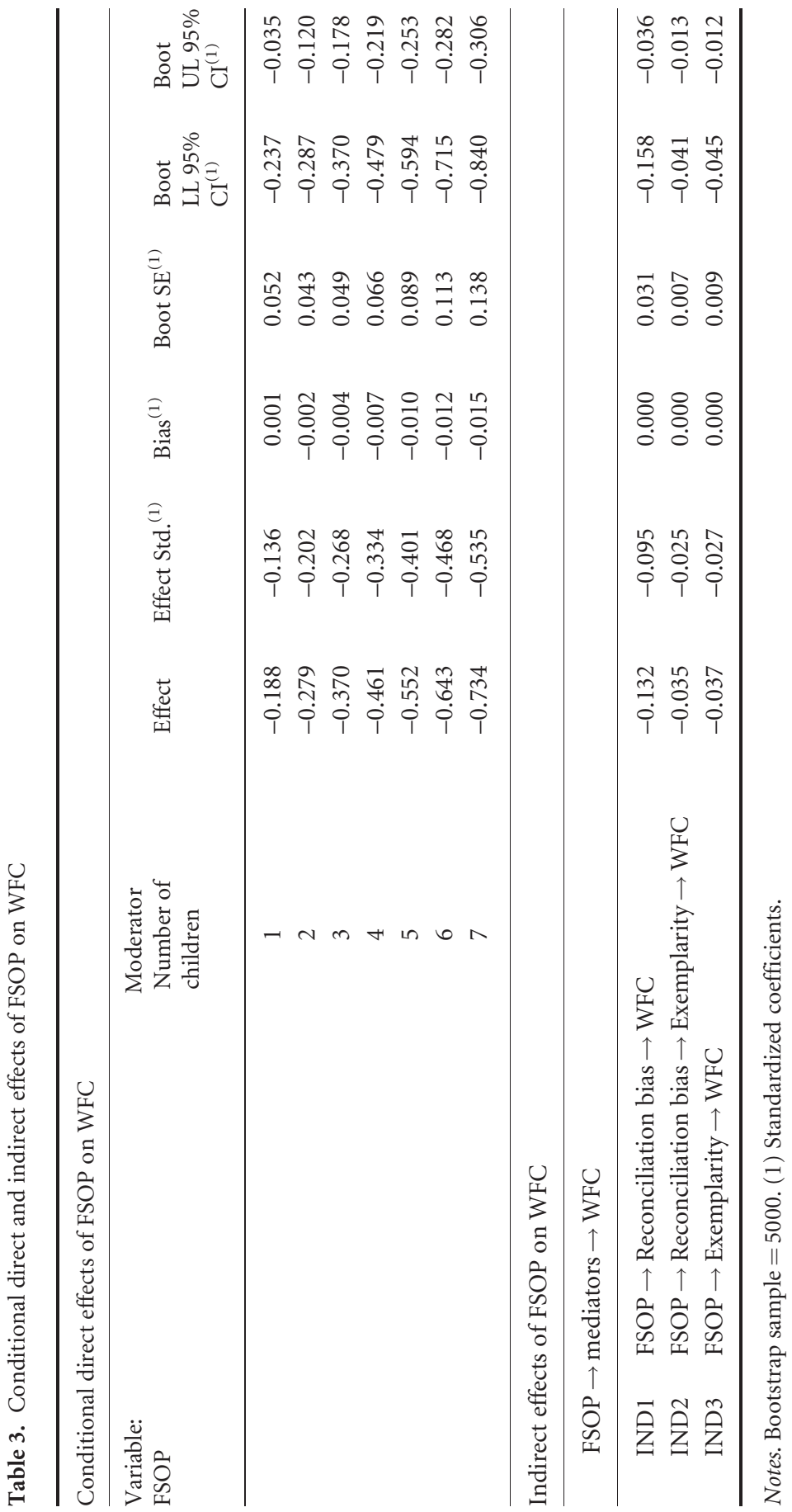


value of the "Reconciliation bias" variable and a higher value of the "Exemplarity" variable constitute an indicator that the corporate culture of the company provides a "conversion factor" or "resource" to the fathers that expands their capability of choice in the area of work-life balance, and this should lead to a use of reconciliation measures by these fathers closer to what they would really like to do (in the absence of corporate barriers), which would reduce their levels of WFC.

Furthermore, the fact that a lesser "Reconciliation bias" also indirectly reduces the WFC through the mediating variable "Exemplarity" supports hypothesis 2 (fathers who work in firms where reconciliation bias is low have the perception that in their firms there is a greater exemplarity in the use of reconciliation measures by men and male managers).

A research question we were interested to clarify in this article (from the information collected from a sample of fathers employed in organizations) was to what extent family-supportive organizations tend to conceive the reconciliation as something associated mainly with the female staff or, on the contrary, if these types of companies have a more advanced culture and are organizations where the corporate barriers against the reconciliation of the men are smaller. Hypothesis 3 specified this second possibility (fathers working in FSOP firms have the perception that in their firms there is less bias against father's reconciliation and greater effective use of reconciliation measures by men and male managers) and that is what our results seem to indicate (table 2): the fact that the father works in a family-supportive organization has a negative effect on "Reconciliation bias" $(\beta=-0.691$, $p=0.000)$ and a positive effect on "Exemplarity" $(\beta=0.187, p=0.000)$.

According to hypothesis 4 , working in a family-supportive organization reduces the WFC of the fathers directly, but also reduces the WFC indirectly, through its effect on "Reconciliation bias" and on "Exemplarity." As discussed above, according to the terminology used by Hayes (2013), this structure of relations is a case of "serial multiple mediator model with two mediators." In this kind of model there are three indirect effects: IND1 (FSOP $\rightarrow$ Reconciliation bias $\rightarrow$ WFC); IND2 $\quad($ FSOP $\rightarrow$ Reconciliation $\quad$ bias $\rightarrow$ Exemplarity $\rightarrow$ WFC); and IND3 (FSOP $\rightarrow$ Exemplarity $\rightarrow$ WFC). As can be seen in table 2 , all these paths are statistically significant. In turn, table 3 shows the estimates of each of these three indirect effects: IND1 $=-0.095$, bootstrap 95\% CI $[-0.158,-0.036]$; IND2 $=-0.025$, bootstrap 95\% CI $[-0.041,-0.013]$; and IND3 $=-0.027$, bootstrap 95\% CI $[-0.045,-0.012]$.

On the other hand, the direct effect of FSOP on WFC (not shown in the tables) is negative and statistically significant $(\beta=-0.204, p=0.000)$. Nevertheless in our model we considered that this direct effect of FSOP on WFC was moderated by the variable "Number of children" (we introduced in the third equation, in table 2, the variable "Number of children" and an interaction variable, "FSOP $\times$ Number of children"). So now the direct effect of FSOP on WFC is dependent, or conditional, on the number of children. Our 
results confirm this moderating effect (see table 2): the interaction "FSOP $\times$ Number of children" was statistically significant $(\beta=-0.271$, $p=0.021)$. Now, for instance, when the number of children $=1$, the direct effect of FSOP on WFC is -0.136 , bootstrap 95\% CI [ $-0.237,-0.035]$; when the number of children $=2$, this direct effect is -0.202 , bootstrap 95\% CI $[-0.287$, $-0.120]$; and when the number of children $=3$ this direct effect is -0.268 , bootstrap $95 \%$ CI $[-0.370,-0.178]$. So, according to hypothesis 5 , the higher the number of children, the greater the direct effect of FSOP on WFC (see figure 2).

And finally, it is possible to obtain the total effect (sum of indirect and direct effects) of FSOP on WFC conditional on the number of children. For example, if the number of children is three, the total effect of FSOP on WFC is -0.416 (so two cases that differ by one standard deviation of FSOP are estimated to differ by -0.416 standard deviation of WFC).

Summarizing, according to our results, working in a family-supportive organization seems to be associated, direct and indirectly, with a reduction in the father's perception of WFC.

Regarding the six control variables used in our model, all of them are statistically significant (with respect to any of the three endogenous variables) and have the expected sign. Working in the public sector (usually a familyfriendly working place) is associated with less WFC $(\beta=-0.105, p=0.000)$. But also it is associated with less "Reconciliation bias" $(\beta=-0.083, p=0.001)$. For example, Meil, Romero-Balsas, and Rogero-García (2017a) state that in work environments where legal protection is higher, such as in the Spanish public sector as compared to the private sector, there is more acceptance for fathers using reconciliation measures (in their study they analyzed fathers using parental leaves alone). Having a long working week increases the father's perception of WFC $(\beta=0.145, p=0.000)$ (similar results were found in Grandey, Cordeiro, and Michael 2007 and Thompson and Prottas 2005). Higher earnings are associated with more WFC $(\beta=0.108, p=0.000)$ (usually better paid jobs are associated with more work demands). Working in a large organization is associated with more "Exemplarity" $(\beta=0.193, p=0.000)$ (usually large companies have more developed reconciliation policies and, according to this result, the fathers who work in this type of company would have the perception that in their organizations men use the reconciliation measures more). Having more daily hours for care reduces the father's WFC $(\beta=-0.162, p=0.000)$. And finally, "Mother's satisfaction with the family" tends to reduce the father's WFC $(\beta=-0.104, p=0.000)$. This is an interesting result. It reminds us that father's individual decisions regarding the allocation of time at work and household are in fact the result of intra-family negotiations. Everything else constant, how the mother perceives her satisfaction with the family or with her work-family balance may influence the father's perception of his own work-family balance. 


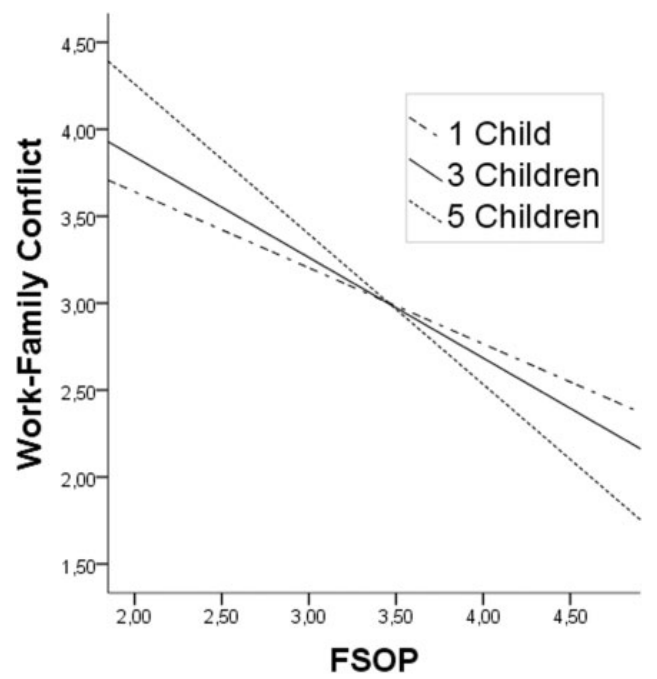

Figure 2 The moderating impact of number of children (one, three, and five children) on the direct effect of FSOP on WFC.

\section{Discussion}

In this article we have dealt with a problem related to the organizational culture of companies (from the information collected from a sample of fathers employed in them). On the one hand, companies are still affected (at least in Spain) by significant inertia concerning the ideal worker. The work is designed for people who, when they have family responsibilities, delegate care to someone else (traditionally a stay-at-home wife). On the other hand, the profile of workers has undergone a step change. Almost half of them (female employees), when they become mothers, need to balance work with family life; and the other half (male employees), when they become fathers, need something very similar to what women require (for instance, 83.2 percent of the fathers of our sample were strongly or somewhat in agreement with the statement that "a man can be as capable as a woman at caring for his baby and connecting emotionally with him"). But for mothers, reaching a workfamily balance and making use of the reconciliation measures is still viewed as "something compulsory," whereas for fathers these facts are still seen as optional. And given the organizational pressure of the ideal worker, finally it is women who in large part use these measures and, consequently, they are those on whom the motherhood penalty falls (Correll, Benard, and Paik 2007), 
while concerning the fathers there is a growing sense of WFC, precisely because they do not use such reconciliation measures. This gender inequality in the request and use of reconciliation measures is incorporated as an unwritten norm of the organizational culture of the company. And this area of inequality constitutes a barrier that limits the capability (agency) of many fathers to request those measures that they theoretically have at their disposal.

In this context it is very important to take into account the variability that may exist between companies with regard to the culture of support for reconciliation. What this article shows, for the case of Spain, is that in companies that have an organizational culture of support for reconciliation for their workers, the pressure exerted by the ideal worker on those who would want to reconcile work and family life and, in particular, on fathers, may have relaxed somewhat. As has been shown above, FSOP companies are workplaces where there tends to be less bias against the use of reconciliation measures by men and they are companies where there exists a greater exemplarity in the use of reconciliation measures by males. They are, therefore, companies which, directly or indirectly, tend to produce a smaller agency gap among fathers (with the consequent reduction of their levels of WFC).

In particular, in this article (based on the "capability approach" posed by Adler and Lenz 2017, Drobnič and Guillén-Rodríguez 2011, Hobson 2011, and Hobson and Fahlén 2009) we highlight and present empirical evidence about the fact that not having a bias against men in reconciliation policies, and also having exemplarity in behavior, are organizational factors or "conversion factors" (in Amartya Sen's terminology) that expand the capability of working fathers in the field of work-family balance.

What can be done to reduce the agency gap? According to Correll (2013), if there are no family-friendly laws and if there is no corporate culture of support for the reconciliation of mothers and fathers, the family-friendly policies offered by companies may have the effect of intensifying the negative consequences of the ideal worker norms. As she says, "rather than changing norms, individual accommodation policies instead potentially fuel both ideal worker norms and gender norms by clearly signaling who is not an ideal worker" (in our case, a father using the reconciliation measures).

Governments can reinforce or challenge the traditional gender order (Adler and Lenz 2017). In the specific case of caretaker fathers, or "working fathers" (Ranson 2012), in order to challenge the gender order a very important measure of public policy may be the equalization of parental leaves (equal and non-transferable parental leave for the father and the mother). In the case of Spain this policy change would imply that, in the end, both mother and father would enjoy sixteen weeks of non-transferable and well-paid leave (Castro-García and Pazos 2016; Fernández-Cornejo et al. 2016a). According to Haas and Hwang (2007), this policy seems likely to contribute to men's 
sense of entitlement to support for combining work and family responsibilities, and to their entitlement to use parental leave and other FFMs.

On the other hand, the advances that have taken place in the attitudes and values of the Spaniards have been accompanied by insufficient progress in the institutional framework of support for the egalitarian dual-earner family (Moreno, Ortega, and Gamero-Burón 2017). In this area there is much room for improvement.

And as far as companies are concerned, the offer of reconciliation measures must not be simply an offer of individual accommodation measures, rather it must be accompanied by a culture change; the workplace must cease to be structured by ideas about organizational masculinity and traditional breadwinner norms (Adler and Lenz 2017; Holter 2007); or, in other words, it must cease to be an environment where the "flexibility stigma" problem often arises (Williams, Blair-Loy, and Berdahl 2013). It is necessary to redefine what it means to be a good and productive worker, for example, by recognizing and internalizing the principles that all workers have needs outside of work and that the need to reconcile has no sex. To make progress in this area it is necessary to raise awareness among companies and to transmit to them that this change in their organizational culture is a strategic aspect, or "business case," for a good performance and development of the company. As the results of this article suggest, an organizational advance of this type would shrink the agency gap and reduce the WFC experienced by many fathers. And this would increase the job satisfaction of working fathers (Grandey, Cordeiro, and Michael 2007), with all the positive aspects for the company that this entails. 


\section{Appendix}

Family-Supportive Organizational Perceptions (FSOP) scale (Allen 2001)

1. Work should be the primary priority in a person's life (R)

2. Long hours inside the office are the way to achieve advancement (R)

3. It is best to keep family matters separate from work (R)

4. It is considered taboo to talk about life outside of work (R)

5. Expressing involvement and interest in nonwork matters is viewed as healthy

6. Employees who are highly committed to their personal lives cannot be highly committed to their work $(\mathrm{R})$

7. Attending to personal needs, such as taking time off for sick children, is frowned upon $(\mathrm{R})$

8. Employees should keep their personal problems at home (R)

9. The way to advance in this company is to keep nonwork matters out of the workplace $(\mathrm{R})$

10. Individuals who take time off to attend to personal matters are not committed to their work $(\mathrm{R})$

11. It is assumed that the most productive employees are those who put their work before their family life (R)

12. Employees are given ample opportunity to perform both their job and their personal responsibilities well

13. Offering employees flexibility in completing their work is viewed as a strategic way of doing business

14. The ideal employee is the one who is available 24 hours a day $(\mathrm{R})$

Notes. "(R)" indicates the item is reverse coded so that higher scores indicate more positive perceptions of the organization's support for work/nonwork balance. The items were preceded by the following instructions: "To what extent do you agree that each of the following statements represent the philosophy or beliefs of your organization (remember, these are not your own personal beliefs, but pertain to what you believe is the philosophy of your organization)."

\section{Notes}

Sabina Belope-Nguema is a $\mathrm{PhD}$ student and researcher in the Faculty of Statistical Studies, at the Complutense University of Madrid. She is also a member of the Complutense Research Group "Economic Analysis of Diversity and Equality Policies" (http://www.ucm.es/aedipi).

José Andrés Fernández-Cornejo is Associate Profesor [Profesor Titular] of Applied Economics in the Faculty of Economics and Business Administration, at the Complutense University of Madrid. $\mathrm{He}$ is also co-director of the 
Complutense Research Group "Economic Analysis of Diversity and Equality Policies" (http://www.ucm.es/aedipi).

Lorenzo Escot is Associate Professor [Profesor Titular] of Applied Economics in the Faculty of Statistical Studies, at the Complutense University of Madrid. He is also co-director of the Complutense Research Group "Economic Analysis of Diversity and Equality Policies" (http://www.ucm.es/aedipi).

Eva Del Pozo-García is Associate Professor [Profesor Titular] of Financial Economics in the Faculty of Economics and Business Administration, at the Complutense University of Madrid. She is also a member of the Complutense Research Group "Economic Analysis of Diversity and Equality Policies" (http://www.ucm.es/aedipi).

\section{Acknowledgements}

Special thanks go to Ana Bernabeu, Myriam Martínez, Nacho Cáceres, Cristina Castellanos, and Barry Readman.

\section{Funding}

This research was funded by the Spanish National Plan for Scientific and Technical Research and Innovation, Ref: FEM2014-56723-P.

\section{References}

Abril, Paco, and Alfons Romero 2008. Public and private companies with gender and conciliation policies for men. In Genres, temps sociaux et parentés, ed. P. Gaborit, 217-39. Paris: Harmattan.

Abril, Paco, Teresa Jurado-Guerrero, and Jordi M. Monferrer. 2015. Paternidades en construcción. In Padres y madres corresponsables. Una utopía real, eds. M. J. González and T. Jurado-Guerrero, 100-43. Madrid: Catarata.

Adler, Marina A., and Karl Lenz. 2017. Introduction. In Father involvement in the early years. An international comparison of policy and practice, eds. M.A. Adler and K. Lenz, 1-27. Bristol: Policy Press.

Allen, Tammy D. 2001. Family-supportive work environments: The role of organizational perceptions. Journal of Vocational Behavior 58: 414-35.

Allen, Tammy D., and Jeffrey Greenhaus. 2011. Work-family balance: A review and extension of the literature. Handbook of occupational health psychology. 2nd ed., eds. J. C. Quick and L. E. Tetrick, 165-83. Washington DC: America Psychological Association.

Ashforth, Blake. E., Glen E. Kreiner, and Mel Fugate. 2000. All in a day's work: Boundaries and micro role transitions. Academy of Management Review 25(3): 472-91.

Aumann, Kerstin, Ellen Galinsky, and Kenneth Matos. 2011. The new male mystique. New York: Families and Work Institute. 
Bonney, Jennifer F., Michelle L. Kelley, and Romald F. Levant. 1999. A model of fathers' behavioral involvement in child care in dual-earner families. Journal of Family Psychology 13(3): 401-15.

Burnett, Simon B., Caroline J. Gatrell, Cary. L. Cooper, and Paul Sparrow. 2013. Fathers at work: A ghost in the organizational machine. Gender, Work \& Organization 20(6): 632-46.

Bustelo, María, and Elin Peterson. 2005. Conciliación y (des)igualdad. Una mirada debajo de la alfombra de las políticas de igualdad entre mujeres y hombres. SOMOS Revista de Desarrollo y Educación Popular 7: 32-37.

Castro-García, Carmen, and María Pazos. 2016. Parental leave policy and gender equality in Europe. Feminist Economics 22(3): 51-73.

Clark, Sue Campbell. 2000. Work/family border theory: A new theory of work/family balance. Human Relations 53(6): 747-70.

Conde-Ruíz, José Ignacio, and Ignacio Marra. 2016. Gender gaps in the Spanish labor market, Estudios sobre la Economía Española - 2016/32. Madrid: Fundación de Estudios de Economía Aplicada (FEDEA).

Correll, Shelley, Stephen Benard, and In Paik. 2007. Getting a job: Is there a motherhood penalty? American Journal of Sociology 112(5): 1297-1339.

Correll, Shelley. 2013. Minimizing the motherhood penalty: What works, what doesn't and why? Boston, MA: Research Symposium Gender \& Work, Harvard Business School.

Devreux, Anne Marie. 2007. New fatherhood in practice: Domestic and parental work performed by men in France and in the Netherlands. Journal of Comparative Family Studies 38: 87-103.

Dotti, Giulia Maria. 2017. The economic crisis and changes in work-family arrangements in six European countries. Journal of European Social Policy first published May 12, 2017.

Drobnič, Sonja, and Ana M. Guillén-Rodríguez. 2011. Tensions between work and home: Job quality and working conditions in the institutional contexts of Germany and Spain. Social Politics 18(2): 232-68.

Escot, Lorenzo, José Andrés Fernández-Cornejo, Carmen Lafuente, and C. Carlos Poza. 2012. Willingness of Spanish men to take maternity leave. Do firms' strategies for conciliation impinge on this? Sex Roles, 67(1-2): 29-42.

Eurofound. 2016. Sixth European working conditions survey 2015. Dublin: European Foundation for the Improvement of Living and Working Conditions.

Fernández-Cornejo, José Andrés, Lorenzo Escot, Eva del-Pozo, and Cristina Castellanos-Serrano. 2016a. Do fathers who took childbirth leave become more involved in their children's care? The case of Spain. Journal of Comparative Family Studies 47(2): 169-91.

Fernández-Cornejo, José Andrés, Lorenzo Escot, Jane Kabubo-Mariara, Bethuel Kinyanjui Kinuthia, Guðný Björk Eydal, and Tomas Bjarnason. 2016b. Gender differences in young adults' inclination to sacrifice career opportunities in the future for family reasons: Comparative study with university students from Nairobi, Madrid, and Reykjavik. Journal of Youth Studies 19(4): 457-82.

Finney, Sara J., and Christine DiStefano. 2006. Non-normal and categorical data in structural equation modeling. In Structural equation modeling: A second course, eds. G. R. Hancock and R. O. Mueller, 269-14. Greenwich, CT: Information Age Publishing. 
Fursman, Lindi, and Paul Callister. 2009. Men's participation in unpaid care. A review of the literature. Wellington: Department of Labour, New Zealand Government.

Gatrell, Caroline J., Simon B. Burnett, Cary. L. Cooper, and Paul Sparrow. 2015. The price of love: The prioritisation of child care and income earning among UK fathers. Families, Relationships and Societies 4(2): 225-38.

Goldberg, Julia S. 2015. Identity and involvement among resident and nonresident fathers. Journal of Family Issues 36(7): 852-79.

Goñi-Legaz, Salomé and Andrea Ollo-López. 2016. The impact of family-friendly practices on work-family balance in Spain. Applied Research in Quality of Life 11(3): 983-1007.

Grandey, Alicia A., Bryanne L. Cordeiro, and Judd H. Michael. 2007. Work-family supportiveness organizational perceptions: Important for the well-being of male blue-collar hourly workers? Journal of Vocational Behavior 71: 460-78.

Greenhaus, Jeffrey H., and Nicholas J. Beutell. 1985. Sources of conflict between work and family roles. The Academy of Management Review 10(1): 76-88.

Greenhaus, Jeffrey H., and Gary N. Powell. 2006. When work and family are allies: A theory of work-family enrichment. Academy of Management Review 31: 72-92.

Haas, Linda, and Philip Hwang. 2007. Gender and organizational culture: Correlates of companies' responsiveness to fathers in Sweden. Gender and Society 21(1): 52-79.

Habib, Cherine. 2012. The transition to fatherhood: A literature review exploring paternal involvement with identity theory. Journal of Family Studies 18(2-3): 103-20.

Hayes, Andrew F. 2013. Introduction to mediation, moderation, and conditional process analysis. A regression-based approach. New York: The Guilford Press.

Hobson, Barbara. 2011. The agency gap in work-life balance: Applying Sen's capabilities framework within European contexts. Social Politics 18(2): 147-67.

Hobson, Barbara, and Susanne Fahlén. 2009. Competing scenarios for European fathers: Applying Sen's capabilities and agency framework to work-family balance. Annals of the American Academy of Political and Social Science 624: 214-33.

Holter, Øystein Gullvåg. 2007. Men's work and family reconciliation in Europe. Men and Masculinities 9(4): 425-56.

Kaufman, Gayle. 2013. Superdads. How fathers balance work and family in the 21st Century. New York: University Press.

Kimmel, Michael. 2017. The gendered society. 6th ed. New York: Oxford University Press.

Lamb, Michael E., Joseph H. Pleck, Eric L. Charnov, and James A. Levine. 1985. Paternal behavior in humans. American Zoologist 25: 883-94.

— 1987. A biosocial perspective on paternal behavior and involvement. In Parenting across the lifespan: Biosocial perspectives, eds. J. B. Lancaster, J. Altaman, A. Rossi, and R. L. Sherrod, 11-42. New York: Aldine.

Lapuerta, Irene. 2013. Do regional policies influence the use of parental leave? Revista Española de Investigaciones Sociológicas 141: 29-60.

Levine, James A., and Todd L. Pittinsky. 1997. Working fathers: New strategies for balancing work and family. New York: Addison-Wesley.

Meil, Gerardo. 2013. European men's use of parental leave and their involvement in child care and housework. Journal of Comparative Family Studies 44(5): 557-70.

Meil, Gerardo, Pedro Romero-Balsas, and Jesús Rogero-García. 2017a. Fathers on leave alone in Spain: 'Hey, I want to be able to do it like that, too'. In Comparative perspectives on work-life balance and gender equality. Fathers on leave, eds. M. O'Brien and K. Wall, 107-25. Berlin: Springer. 
2017b. Why parents take unpaid parental leave. Evidence from Spain. In Family Continuity and Change. Comtemporary European Perspectives, eds. V. Cesnuiytè, D. Lück, and E. D. Widmer. Basingstoke: Palgrave-Macmillan.

Moreno, Almudena, Marta Ortega, and Carlos Gamero-Burón. 2017. The family models in Spain: Thinking on the family ambivalence from a theoretical perspective. Revista Española de Sociología 26(2): 149-67.

Netemeyer, Richard G., James S. Boles, and Robert McMurrian. 1996. Development and validation of work-family conflict and family-work conflict scales. Journal of Applied Psychology 81(4): 400-10.

O'Brien, Margaret, and Moss Peter. 2010. Fathers, work and family policies in Europe. In The role of the father in child development, ed. M. E. Lamb, 551-57. New York: Wiley.

OECD (2017). OECD Economic surveys: Spain 2017. Paris: OECD Publishing.

Olmstead, Spencer B., Ted G. Futris, and Kay Pasley. 2009. An exploration of married and divorced, nonresident men's perceptions and organization of their father role identity. Fathering 7(3): 249-68.

Pasamar, Susana, and Joaquín Alegre. 2015. Adoption and use of work-life initiatives: Looking at the influence of institutional pressures and gender. European Management Journal 33: 214-24.

Pérez-Caramés, Antía (2014). Family policies in Spain. In Handbook of family policies across the globe, ed. M. Robila, 175-94. New York: Springer.

Ranson, Gillian. 2012. Men, paid employment and family responsibilities: Conceptualizing the 'working father'. Gender, Work \& Organization 19(6): 741-61.

Rehel, Erin, and Emily Baxter. 2015. Men, fathers, and work-family balance. Washington, DC: Center for American Progress.

Robeyns, Ingrid. 2003. Sen's capability approach and gender inequality: Selecting relevant capabilities. Feminist Economics 9(2): 61-92.

Romero-Balsas, Pedro, Dafne Muntanyola-Saura, and Jesús Rogero-García. 2013. Decision-making factors within paternity and parental leaves: Why Spanish fathers take time off from work. Gender, Work and Organization 20(6): 678-91.

SAS Institute Inc. (2015). SAS/STAT 14.1 user's guide. Cary, NC: SAS Institute Inc.

Sen, Amartya. 1989. Development as capability expansion. Journal of Development Planning 19: 41-58.

1993. Capability and well-being, in The quality of life, eds. M. Nussbaum, and A. Sen, 30-53. Oxford: Clarendon Press.

1999. Development as freedom. Oxford: Oxford University Press.

Stryker, Sheldon. 1968. Identity salience and role performance: The relevance of symbolic interaction theory for family research. Journal of Marriage and Family 30(4): 558-64.

Sugden, Robert. 1993. Welfare, resources, and capabilities: A review. Journal of Economic Literature 31(4): 1947-1962.

Thompson, Cynthia A., and David Prottas. 2005. Relationships among organizational family support, job autonomy, perceived control, and employee well-being. Journal of Occupational Health Psychology 10(4): 100-18.

Valiente, Celia. 2013. Gender equality policymaking in Spain (2008-11): Losing momentum. In Politics and society in contemporary Spain: From Zapatero to Rajoy, eds. B. N. Field and A. Botti, 162-79. New York: Palgrave Macmillan.

Williams, Joan C., Mary Blair-Loy, and Jennifer L. Berdahl. 2013. Cultural schemas, social class, and the flexibility stigma. Journal of Social Issues 69(2): 209-34. 